\title{
Scanning supersaturation condensation particle counter applied as a nano-CCN counter for size-resolved analysis of the hygroscopicity and chemical composition of nanoparticles
}

\author{
Z. Wang ${ }^{1}$, H. Su ${ }^{1}$, X. Wang ${ }^{1}$, N. Ma ${ }^{2}$, A. Wiedensohler ${ }^{2}$, U. Pöschl ${ }^{1}$, and Y. Cheng ${ }^{1}$ \\ ${ }^{1}$ Multiphase Chemistry Department, Max Planck Institute for Chemistry, Mainz 55128, Germany \\ ${ }^{2}$ Leibniz Institute for Tropospheric Research, Leipzig 04318, Germany \\ Correspondence to: H. Su (h.su@mpic.de) and Y. Cheng (yafang.cheng@mpic.de) \\ Received: 18 October 2014 - Published in Atmos. Meas. Tech. Discuss.: 17 November 2014 \\ Revised: 2 April 2015 - Accepted: 21 April 2015 - Published: 21 May 2015
}

\begin{abstract}
Knowledge about the chemical composition of aerosol particles is essential to understand their formation and evolution in the atmosphere. Due to analytical limitations, however, relatively little information is available for sub-10 $\mathrm{nm}$ particles. We present the design of a nano-cloud condensation nuclei counter (nano-CCNC) for measuring size-resolved hygroscopicity and inferring chemical composition of sub- $10 \mathrm{~nm}$ aerosol particles. We extend the use of counting efficiency spectra from a water-based condensation particle counter (CPC) and link it to the analysis of $\mathrm{CCN}$ activation spectra, which provides a theoretical basis for the application of a scanning supersaturation CPC (SS$\mathrm{CPC}$ ) as a nano-CCNC. Measurement procedures and data analysis methods are demonstrated through laboratory experiments with monodisperse particles of diameter down to $2.5 \mathrm{~nm}$, where sodium chloride, ammonium sulfate, sucrose and tungsten oxide can be easily discriminated by different characteristic supersaturations of water droplet formation. A near-linear relationship between hygroscopicity parameter $\kappa$ and organic mass fraction is also found for sucroseammonium sulfate mixtures. The design is not limited to the water CPC, but also applies to CPCs with other working fluids (e.g. butanol, perfluorotributylamine). We suggest that a combination of SS-CPCs with multiple working fluids may provide further insight into the chemical composition of nanoparticles and the role of organic and inorganic compounds in the initial steps of atmospheric new particle formation and growth.
\end{abstract}

\section{Introduction}

New particle formation (NPF) and subsequent growth have been intensively studied owning to their important roles in air pollution and climate (Kulmala et al., 2000, 2014; Kerminen et al., 2012; Zhang et al., 2012). Chemical composition of the newly formed particles is key for understanding the production and transformation of atmospheric aerosol particles. Though sulfuric acid has been commonly recognized as a key species in NPF, it is not sufficient to explain the observed particle growth rate (Kulmala et al., 2013). Organics make up a large fraction in the Aitken and accumulation modes of atmospheric aerosols, but their role in the NPF is still not clear due to the lack of measurement data in the corresponding size range (nucleation mode).

A number of apparatuses have been developed to characterize the chemical compositions of ultrafine particles (Fig. 1). Aerosol mass spectrometer (AMS) can measure particles with diameters down to $\sim 40 \mathrm{~nm}$ (Jayne et al., 2000 and updated references on http://cires.colorado.edu/jimenez/ ams-papers.html). Thermal desorption chemical ionization mass spectrometer (TDCIMS; Smith et al., 2004) and nano aerosol mass spectrometer (NAMS; Wang and Johnston, 2006) are commonly used at $10-30 \mathrm{~nm}$ particles. Analysis of molecular clusters with diameter up to $\sim 1 \mathrm{~nm}$ has been achieved by cluster chemical ionization mass spectrometer (Cluster-CIMS; Zhao et al., 2010; Jiang et al., 2011a) and chemical ionization with the atmospheric pressure interface time-of-flight mass spectrometer (CI-APi-TOF; Jokinen et al., 2012). However, direct chemical composition measurement of sub- $10 \mathrm{~nm}$ particles is still difficult due to its rel- 


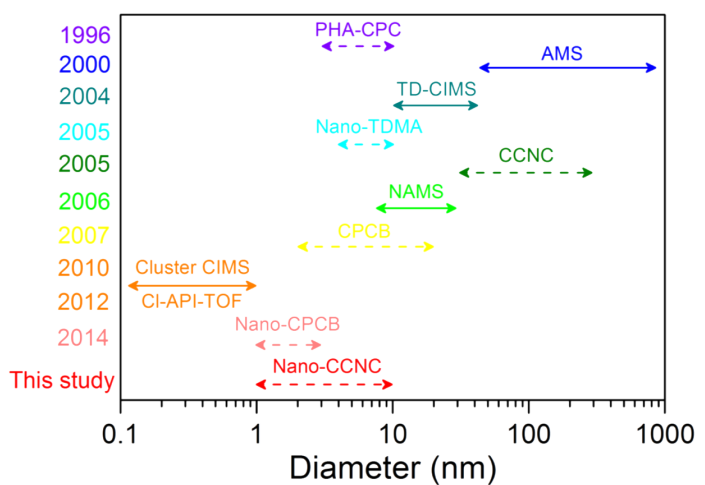

Figure 1. Direct and indirect methods for measurement/estimation of atmospheric aerosol chemical composition (modified from Kulmala et al., 2012). The year when each technique was first reported is indicated on the left-hand side. The solid arrowheads indicate the direct measurements, whereas dashed arrowheads represent the indirect measurements. The use of scanning supersaturation CPC (SS-CPC) as nano-CCNC introduced in this study mainly focus on the size range of $1-10 \mathrm{~nm}$.

atively low transmission efficiency and mass concentration (Kulkarni et al., 2011). Therefore, alternative (indirect) methods have been developed, which infer the chemical composition information of nanoparticles through measurements of physical properties (e.g., hygroscopicity, volatility and solvent affinity), such as the nano-tandem differential mobility analyzer (nano-TDMA; Sakurai et al., 2005; Ehn et al., 2007), pulse-height condensation particle counter (PH-CPC; Marti et al., 1996; Saros et al., 1996; Weber et al., 1998; O'Dowd et al., 2002, 2004; Sipilä et al., 2009) and CPC Battery (CPCB; Kulmala et al., 2007; Riipinen et al., 2009; Kangasluoma et al., 2014).

The ability of aerosol particles to serve as cloud condensation nuclei $(\mathrm{CCN})$, i.e., to initiate the formation of droplets by condensation of water vapor, is closely linked to their chemical composition. Size-resolved measurements have shown that atmospheric aerosol particle hygroscopicity and $\mathrm{CCN}$ activity are closely correlated with particle composition expressed as organic and inorganic mass fractions determined by aerosol mass spectrometry (Dusek et al., 2006, 2010; Gunthe et al., 2009, 2011; Jurányi et al., 2010; Rose et al., 2010, 2011, 2013; Cerully et al., 2011; Lance et al., 2013; Lathem et al., 2013; Mei et al., 2013; Wu et al., 2013). Hygroscopicity distributions derived from size-resolved $\mathrm{CCN}$ measurements also provide insight into the mixing state of aerosol particles (Lance, 2007; Su et al., 2010). Widely used $\mathrm{CCN}$ counters based on the continuous-flow thermal gradient technique can potentially measure at water vapor supersaturations up to $6 \%(S=($ saturation ratio -1$) \cdot 100 \%$; Lance et al., 2006). Traditionally, however, atmospheric CCN measurements were mostly focusing on supersaturations less than $\sim 1 \%$ corresponding to particle activation sizes above $\sim 30 \mathrm{~nm}$ as referenced above. For the activation of sub-10 nm

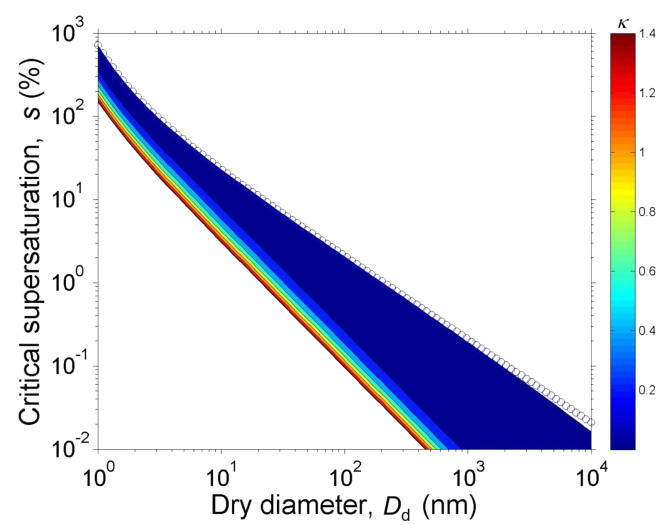

Figure 2. Critical water vapor supersaturation for the activation of particles with different dry diameter and chemical composition. The color bar indicates the $\kappa$ values. The open circles are references to water droplets.

particles, higher levels of water vapor supersaturation are required as shown in Fig. 2 as a function of particle size and hygroscopicity. In the atmosphere, supersaturations $>1 \%$ are less common but do occur in convective clouds (Pruppacher and Klett, 2000), especially at low aerosol concentrations and high updraft velocities (aerosol-limited regime of CCN activation; Pöschl et al., 2010).

In this study, we present the concept of a nano-CCNC for measuring hygroscopicity and inferring chemical composition of nanoparticles in the diameter range of $\sim 2-10 \mathrm{~nm}$. The method builds on recent progresses in size-resolved $\mathrm{CCN}$ measurements of ultrafine aerosol particles as referenced above. We first explain the theoretical basis, instrument setup and the data retrieval methodology. Subsequently, we report experimental data for a proto-type nano-CCNC and its performance in discriminating different substances. Finally, we discuss potential applications of the nano-CCNC in field and laboratory experiments in combination with other techniques.

\section{Design and operation}

\subsection{CPC versus CCNC}

The activation of sub- $10 \mathrm{~nm}$ particles with water vapor requires a higher supersaturation $S$, which goes beyond the measurement range of most $\mathrm{CCN}$ counters, but falls into the range of water-based CPC. The water CPC is based on a similar working principle as a CCNC but running at a much higher $S$ (Hering et al., 2005). High $S$ reduces the critical activation size of particles so that "almost all" interested particles can be activated and detected (McMurry, 2000a, b). In theory, the counting efficiency curve of the CPC reflects the same composition dependence of aerosol particles as in the 


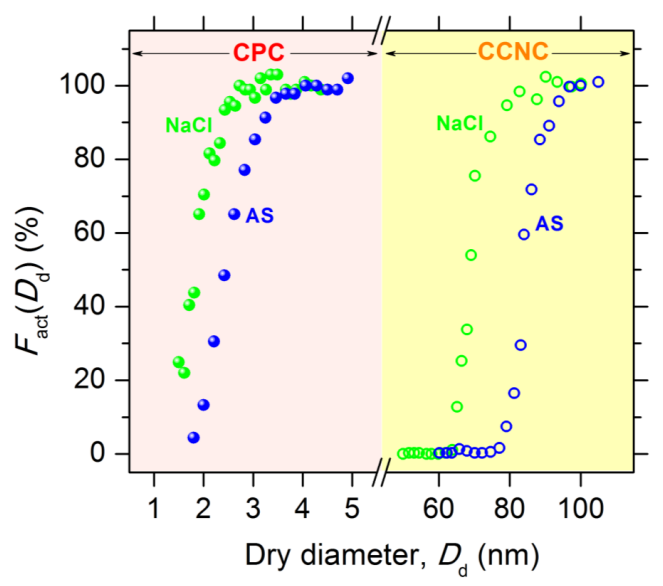

Figure 3. The symmetry between counting efficiency of a CPC (condensation particle counter, TSI model 3786) and the activation curve of a CCNC (cloud condensation nuclei counter, DMT $\mathrm{CCNC}$ ). The green and blue circles represent the results for sodium chloride $(\mathrm{NaCl})$ and ammonium sulfate (AS) particles, respectively. The CPC was operated with a growth tube temperature and a saturator temperature of 78 and $8^{\circ} \mathrm{C}$, respectively (Mordas et al., 2008). The CCNC was operated with a temperature difference of $4.5 \mathrm{~K}$ across the growth chamber (Moore et al., 2010).

activation curve of the $\mathrm{CCNC}$, but is extended to smaller size ranges (Fig. 3).

In practice, $\mathrm{CPCs}$ and $\mathrm{CCNCs}$ have different applications by making use of different parts of their activation curves. As shown in Fig. 3, the CPC is mainly used for the accurate particle counting, ideally operated at size ranges with activation fractions $\left(F_{\text {act }}\right)$ equal to 1 . The size-resolved CCN measurements are often designed to determine the whole activation curves, especially the composition-sensitive parts with $F_{\text {act }}$ varying between 0 and 1 .

\subsection{Design and operation of nano-CCNC}

Our nano-CCNC system adopted a similar design from previous size-resolved CCN measurements (Rose et al., 2008; Moore et al., 2010). Figure 4 exhibited the schematic of the whole system. It comprises of a nano-differential mobility analyzer (nano-DMA), a total particle counter (electrometer or ultrafine CPC with smaller critical detection size) and a nano-CCNC along with a neutralizer. The nano-CCNC is a water-based CPC with a control unit regulating the scan of $S$.

The measuring protocol of nano-CCNC is (1) to use a nano-DMA to select monodisperse particles of certain dry diameter $\left(D_{\mathrm{d}}\right)$; and (2) to measure the number concentration of total particles $\left(N_{\text {tot }}\right)$ by the total particle counter and activated particles $\left(N_{\text {act }}\right)$ at varied $S$ by SS-CPC, respectively. This results in a size and supersaturation-resolved activation fraction, $F_{\text {act }}=f\left(D_{\mathrm{d}}, S\right)$. By scanning $D_{\mathrm{d}}$ and $S$, the whole 3-D activation spectra over the $D_{\mathrm{d}}-S$ plane can be achieved

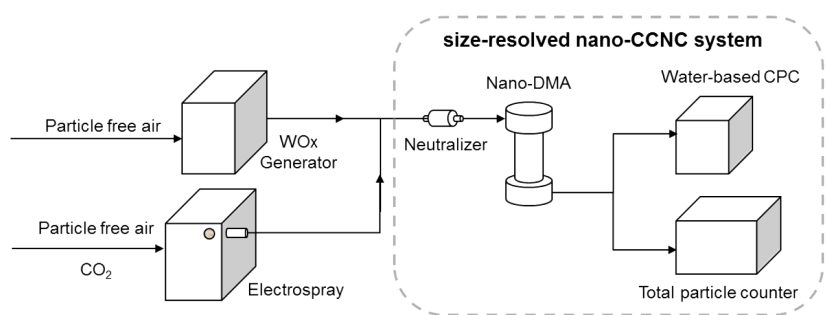

Figure 4. Schematic of the laboratory calibration. The proposed size-resolved nano-CCNC system is marked within the dashed box.

(Su et al., 2010). In practice, people can first keep $D_{\mathrm{d}}$ constant and vary $S$, then select another value of $D_{\mathrm{d}}$ and iterate the procedure as the " $S$ scan" mode in $C C N$ measurements (Dusek et al., 2006; Moore and Nenes, 2009; Snider et al., 2010). Alternatively, we could also first keep $S$ constant and vary $D_{\mathrm{d}}$ as the " $D_{\mathrm{d}}$ scan" mode (Petters et al., 2009; Wiedensohler et al., 2009; Rose et al., 2011).

The scan of $S$ can be achieved by (1) scanning the temperature gradient between the saturator and growth tube (by changing the saturator or growth tube temperature; Mordas et al., 2008; Kupc et al., 2013); (2) scanning the mixing ratio of saturator air and dilution air (Gallar et al., 2006) or saturator flow and aerosol flow (Vanhanen et al., 2011; Wimmer et al., 2013; Lehtipalo et al., 2014). The former approach, however, has not been actively pursued partly due to the relatively slow thermal response, limiting the time resolution of measurement to tens of minutes with current CPCs (McDermott et al., 1991). However, if we are only interested in a narrow size range, i.e., sub- $10 \mathrm{~nm}$ or even a single size, it is still a feasible option, because relatively small number of sizes needs to be scanned. The scanning flow approach has better time resolution. In the work of Gallar et al. (2006), the flow scan is achieved by varying the mixing ratio of saturator and dilution air and their main purpose is to obtain particle size spectrum. After using fast-response flow controllers, time response of CPC (with a perfluorinated organic compound as the working fluid) could reach $\sim 1$ second to the change of supersaturation.

\subsection{Measurement procedure and data analysis}

Concerning the application of nano-CCNC, we proposed the following procedure. The first step is to characterize the calibration curve $H(S)$; i.e., the cumulative supersaturation distribution of $S$ that aerosol particles have been exposed to in the CPC, which will then be used to determine the characteristic activation supersaturation and hygroscopicity of aerosol samples for inferring chemical composition.

\subsubsection{Determination of supersaturation distribution}

For particles of the same composition, their ideal activation curves would be a step function according to the Köhler the- 

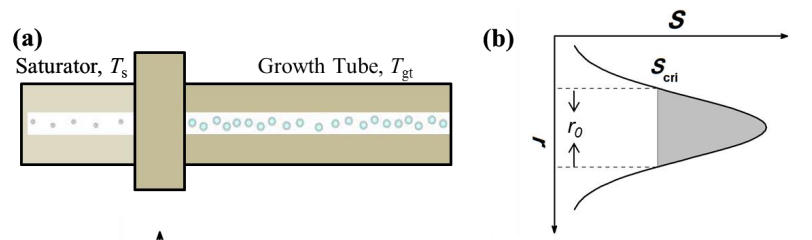

(c)
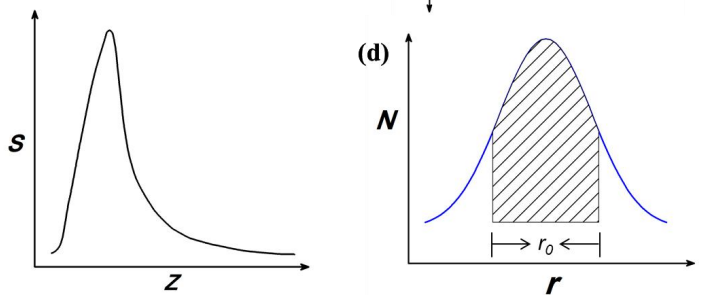

Figure 5. (a) Structure of the water CPC 3788 from TSI; schematic supersaturation $S$ profiles (b) in the radial and (c) streamwise (according to Kulmala et al., 2007); the gray shadow represents the area where $S$ is larger than the $S_{\text {cri }}$ (critical supersaturation); $r$ is the distance from the centerline and $Z$ is the distance from the starting point of the growth tube. (d) Radial distribution of activated particles (areas with black lines); blue line is the schematic particle number distribution in the growth tube. The activated areas are determined by the distance along the radials shown in Fig. $5 b$.

ory. However, the observed activation curves in Fig. 3 turn out to be a rather broad distribution. The broadening of the activation curves can be attributed to (1) the non-uniform and broad distribution of $S$ that particles have been exposed to in the CPC; (2) the transfer function of DMA, especially for smaller nanoparticles due to diffusional effects (Stolzenburg, 1988); and (3) the doubly/multiply charged particles. For the latter two factors, the influence of doubly/multiply charged particles can be minimized by carefully adjusting the size distribution of calibration aerosols (so that the investigated diameter lies on the right side of the mode diameter of calibration aerosols). The DMA transfer function is not the dominant factor for the observed broadening. For example, at particle diameter of $\sim 2-3 \mathrm{~nm}$, the DMA transfer function (TSI nano-DMA model 3085) only contributes to $\sim 36 \%$ of the overall broadened width, while the rest can be attributed to the non-uniformity of $S$. The value of $36 \%$ is calculated from a $\sim 18 \%$ NFWHM (normalized full width at half maximum) of the DMA transfer function (Chen et al., 1998; Stolzenburg and McMurry, 2008; Jiang et al., 2011b) and $\mathrm{a} \sim 50 \%$ NFWHM for the observed activation curves (Kupc et al., 2013).

Figure 5 explains the origin of the non-uniformity of exposed $S$ in the CPC. In the aerosol activation unit (growth tube, Fig. 5a), $S$ is not evenly distributed ( $S$ has a maximum in the centerline and a zero value at the wall, Fig. 5b). Due to finite dimensions of the sample capillary, particle dispersions and its size dependence (Stolzenburg and McMurry, 1991), aerosol particles in the growth tube are not uniformly distributed as well. By overlaying the spatial distribution of $S$ with that of aerosol particles, we can determine $H(S)$, i.e., the cumulative supersaturation distribution of $S$ that aerosol particles have been exposed to in the growth tube. Fig. $5 \mathrm{~b}$ suggests that $H(S)$ turns out to be a broad distribution instead of a step function. As a mapping of $H(S)$, the activation curve $F_{\text {act }}\left(D_{\mathrm{d}}\right)$ will also be a broad distribution. The conversion between $H(S)$ and $F_{\text {act }}\left(D_{\mathrm{d}}\right)$ is given in the following.

By assuming a dominant role of $S$ non-uniformity in the broadening effect, we have the following mathematical expression for the observed activation fraction $F_{\text {act }}\left(D_{\mathrm{d}}\right)$ :

$$
\begin{aligned}
F_{\text {act }}\left(D_{\mathrm{d}}\right) & =\frac{\int n_{\mathrm{N}}(S)(1-H(S)) \mathrm{d} S}{\int n_{\mathrm{N}}(S) \mathrm{d} S} \\
& =\frac{\int n_{\mathrm{N}}(S)(1-H(S)) \mathrm{d} S}{N_{\text {tot }}} \\
& =\int \frac{n_{\mathrm{N}}(S)}{N_{\text {tot }}}(1-H(S)) \mathrm{d} S \\
& =\int n_{\mathrm{N}}^{*}(S)(1-H(S)) \mathrm{d} S,
\end{aligned}
$$

where $n_{\mathrm{N}}(S)$ is the aerosol number distribution as a function of its critical activation supersaturation; $n_{N}(S) \mathrm{d} S$ equals number concentration of particles in the critical supersaturation range of $S$ to $S+\mathrm{d} S$ and $n_{\mathrm{N}}^{*}(S)=n_{\mathrm{N}}(S) / N_{\text {tot }}$ is the normalized distribution. According to the Köhler theory, particles of identical size and composition have the same $S_{\text {cri }}$ and the corresponding $n_{\mathrm{N}}^{*}(S)$ becomes a Dirac delta function, or $\delta$ function. Substituting $n_{\mathrm{N}}^{*}(S)=\delta\left(S-S_{\text {cri }}\right)$ into Eq. (1) gives

$$
F_{\text {act }}\left(D_{\mathrm{d}}\right)=\int \delta\left(S-S_{\text {cri }}\right)\left(1-H\left(S_{\text {cri }}\right)\right) \mathrm{d} S=1-H\left(S_{\text {cri }}\right) .
$$

Then we have the value of the cumulative distribution function $(\mathrm{CDF})$ at $S_{\text {cri }}, H\left(S_{\text {cri }}\right)=1-F_{\text {act }}\left(D_{\mathrm{d}}\right)$, in which $S_{\text {cri }}$ can be determined by solving different Köhler equations for the maximum $S$.

By changing $S_{\text {cri }}$ of aerosol samples, we could scan through the $S$ space and get the whole distribution of $H(S)$. In practice, the scanning of supersaturation can be achieved by scanning $D_{\mathrm{d}}$. Equation (2) is actually suggesting that the supersaturation distribution $H(S)$ that aerosol particles experienced in the CPC can be determined from counting efficiency spectra of compounds with known activation properties.

\subsubsection{Determination of characteristic supersaturation and hygroscopicity}

Once the whole distribution $H=f(S)$ is determined, the characteristic activation $S$ for a monodisperse unknown compounds can be directly calculated from its inverse function:

$S=f^{-1}(H)=f^{-1}\left(1-F_{\text {act }}\right)$.

Then the particle hygroscopicity parameter $\kappa$ can be determined from the $\kappa-S_{\text {cri }}$ relationship. An approximate expression is given below (Petters and Kreidenweis, 2007; Su et al., 
2010):

$\kappa \approx \frac{4 A^{3}}{27 D_{\mathrm{d}}^{3} \ln ^{2}\left(1+S_{\mathrm{cri}} /(100 \%)\right)}$ and $A=\frac{4 \sigma_{\mathrm{sol}} M_{\mathrm{w}}}{\rho_{\mathrm{w}} R T}$,

where $M_{\mathrm{w}}$ and $\rho_{\mathrm{w}}$ are the molar mass and density of water, and $\sigma_{\text {sol }}$ is the surface tension of the solution droplet. $R$ and $T$ are the universal gas constant and absolute temperature, respectively.

Equation (3) refers to monodisperse particles of a single activation $S$. It becomes more complicated when monodisperse particles with multiple activation supersaturations are considered (externally mixed aerosol particles). The mathematical solution to this problem is explained as follows. By discretizing the right hand side of Eq. (1) into $J$ bins, we have $F_{\text {act }}$ as a linear combination of $n_{\mathrm{N}}^{*}$

$F_{\mathrm{act}, i}=\sum^{J} n_{\mathrm{N}}^{*}\left(S_{j}\right)\left(1-H_{i}\left(S_{j}\right)\right) \Delta S=\sum^{J} a_{i, j} x_{j}$,

where $j$ denotes the bin number of $S$; $i$ denotes the $i$ th $H(S)$ distribution (because we can measure the same kind of aerosol particles with CPCs of different $H$ ). The $a_{i, j}$ and $x_{j}$ are introduced here for simple illustration, in which $a_{i, j}$ is a known parameter, $a_{i, j}=\left(1-H_{i}\left(S_{j}\right)\right) \Delta S$ and $x_{j}=n_{\mathrm{N}}^{*}$ is an unknown. Finally, $n_{\mathrm{N}}^{*}$ can be solved by constructing a series of independent equations, i.e., total number of $i$, $I$, should meet the equation with $I \geq J$. A complete data retrieval method will be presented in a following paper, in which the DMA transfer function, size dependence of $H(S)$, particle shape factors and mixing states will be considered along with the $S$ distribution. In addition, size-effect on the thermodynamic parameters should also be addressed for a more accurate description of the Köhler theory (Cheng et al., 2015).

\subsubsection{Ambient measurement}

With a given activation fraction $F_{\text {act }}$, we can infer the $S_{\text {cri }}$ from the supersaturation distribution $H(S)$. However, in most cases, the low concentration/count of sub-10 nm particles challenges our instrument because the electrometer can only be operated reliably at high concentration level (> $1000 \mathrm{~cm}^{-3}$; Wiedensohler et al., 1994), which is basically never the case for size-resolved measurement at ambient condition. To overcome this problem, we propose the use of relative activation ratio $R_{H / H_{0}}$, which is defined as the ratio of activation fraction at one $H(S)$ distribution to that of the other $H_{0}(S)$ distribution:

$$
\begin{aligned}
R_{H / H_{0}} & =F_{\text {act }, T} / F_{\text {act }, T_{0}} \\
& =\left(N_{\text {act }, T} / N_{\text {tot }}\right) /\left(N_{\text {act }, T_{0}} / N_{\text {tot }}\right)=N_{\text {act }, T} / N_{\text {act }, T_{0}},
\end{aligned}
$$

in which $T$ and $T_{0}$ correspond to the different saturator temperature $T_{\mathrm{s}}, N_{\mathrm{act}, T}$ and $N_{\mathrm{act}, T_{0}}$ are CPC counts at $T$ and $T_{0}$, respectively. On the other hand, $R_{H / H_{0}}$ can be determined from two $H(S)$ characterized by calibration aerosols:

$R_{H / H_{0}}=\frac{1-H_{T}(S)}{1-H_{T_{0}}(S)}=g(S)$.

Then the same as Eq. (3), once $R_{H / H_{0}}$ is measured, we can determine:

$S_{\text {cri }}=g^{-1}\left(R_{H / H_{0}}\right)=g^{-1}\left(N_{\text {act }, T} / N_{\text {act }, T_{0}}\right)$.

According to Eq. (6), $R_{H / H_{0}}$ can be measured by two CPCs with different saturator temperature. Electrometer is not needed in this case, and the corresponding detection limit problem no longer exists.

\subsubsection{Summary}

In brief, the data analysis procedure can be summarized as follows.

1. The first step is to determine the size-resolved activation fraction of calibration particles with known hygroscopicity properties, $F_{\text {act }}\left(D_{\mathrm{d}}\right)=N_{\text {act }} / N_{\text {tot }}$. A nanoDMA can be used for the sizing, $N_{\text {act }}$ can be determined by a nano-CCNC and $N_{\text {tot }}$ can be determined by an electrometer or a particle counter that is able to count all particles (e.g., CPC with a lower cutoff size).

2. The second step is to determine $H\left(S_{\text {cri }}\right)$, the cumulative supersaturation distribution that nanoparticles are exposed to in the nano-CCNC, and its inverse function. $H\left(S_{\text {cri }}\right)$ can be calculated from measured $F_{\text {act }}\left(D_{\mathrm{d}}\right)$ by $H\left(S_{\text {cri }}\right)=1-F_{\text {act }}\left(D_{\mathrm{d}}\right)($ Eq. 2$)$ in which $S_{\text {cri }}$ can be calculated based on the Köhler theory. Once $H\left(S_{\text {cri }}\right)$ is determined, we can calculate its inverse function $S_{\text {cri }}=$ $f^{-1}(H)$ (Eq. 3).

3. The last step is to determine the critical supersaturation and corresponding hygroscopicity parameter (e.g., $\kappa$ ) of unknown nanoparticles. Similar to step 1, size-resolved $F_{\text {act }}\left(D_{\mathrm{d}}\right)$ can be measured for other kinds of nanoparticles. Their critical supersaturation at $D_{\mathrm{d}}$ can be directly calculated by $S_{\mathrm{cri}}\left(D_{\mathrm{d}}\right)=f^{-1}\left(1-F_{\mathrm{act}}\left(D_{\mathrm{d}}\right)\right)$, and $\kappa$ can be determined from $S_{\text {cri }}$ and $D_{\mathrm{d}}$ by Eq. (4).

\subsection{Laboratory experimental setup}

To demonstrate applications of the nano-CCNC, we used a WOx generator (Grimm Aerosol Technik, model 7.860; Steiner, 2006) to produce calibration tungsten oxide particles, and use an electrospray aerosol generator (TSI model 3480 ) to generate test nanoparticles (sodium chloride, ammonium sulfate and sucrose). The compress air and $\mathrm{N}_{2}$ were used as carrier gases for the WOx generator and electrospray aerosol generator, respectively. The salt and sucrose solutions were prepared in a standard $20 \mathrm{mM}$ ammonium acetate buffer solution with a conductivity of $0.2 \mathrm{~S} \mathrm{~m}^{-1}$ (siemens per meter; Chen et al., 1995; Kupc et al., 2013). 
As demonstrated in Fig. 4, the generated particles were passed through a neutralizer (Kr85, TSI model 3077), and a TSI nano-DMA (model 3085) was used to select positively charged monodisperse particles. A water-based CPC (TSI model 3788) was used as a nano-CCNC to measure $N_{\text {act }}$ and a Faraday cup electrometer (Grimm Aerosol Technik, model 5.705) was used to measure $N_{\text {tot }}$. The variation of $S$ distribution was achieved by varying the saturator temperature $\left(T_{\mathrm{S}}\right)$ from 284 to $296 \mathrm{~K}$, while the growth tube temperature $\left(T_{\mathrm{gt}}\right)$ was fixed at $348 \mathrm{~K}$. In total, seven $H(S)$ distributions were measured and each temperature adjustment takes $150 \mathrm{~s}$ for stabilization.

\section{Results and discussion}

In the following sections, we will demonstrate the proposed methods with laboratory experimental data for different aerosol particles. We first used WOx particles for the determination of $H(S)$, and then calculated the characteristic $S_{\text {cri }}$ for different kinds of $2.5 \mathrm{~nm}$ particles.

\subsection{Supersaturation distribution}

As previously demonstrated, WOx particle was used to determine the $H(S)$ under the different saturator temperatures. The $S$ distribution that particles experienced inside the nanoCCNC was achieved by measuring the counting efficiency spectra from 2 to $10 \mathrm{~nm}$. Following Eq. (2), we retrieve $H(S)$ from the counting efficiency spectra for WOx particles (Fig. 6). As expected, $H(S)$ was changed considerably by tuning the saturator temperature. Increasing the saturator temperature will reduce the temperature gradient and the supersaturation inside the growth tube. During the data retrieval process, we found that the activation curves for WOx particles represent a bimodal distribution. The following expression of a bimodal lognormal CDF was used to fit the activation curves:

$$
\begin{aligned}
F_{\text {act }}= & (50-a) \cdot\left(1+\operatorname{erf}\left(\frac{D_{\mathrm{d}}-D_{1}}{\sigma_{1} \sqrt{2}}\right)\right) \\
& +a \cdot\left(1+\operatorname{erf}\left(\frac{D_{\mathrm{d}}-D_{2}}{\sigma_{2} \sqrt{2}}\right)\right) .
\end{aligned}
$$

Here, "erf" is the Gauss error function, $a$ is the number fraction for one mode, $D_{1}$ and $D_{2}$ are the geometric mean values of particle diameter, and $\sigma_{1}$ and $\sigma_{2}$ are the standard deviations of the cumulative Gaussian distribution function.

For the conversion of $D_{\mathrm{d}}$ to $S_{\text {cri }}$, we adopt the multilayer adsorption theory accounting for the very low solubility and hygroscopicity for WOx particles. The basic idea is to include an adsorption isotherm (FHH (Frenkel, Halsey and Hill) isotherm in this study) in the traditional Köhler theory instead of the solute term:

$S=\exp \left(\frac{4 \sigma M_{\mathrm{w}}}{R T \rho_{\mathrm{w}} D}\right) \exp \left(-A \Theta^{-B}\right)$,
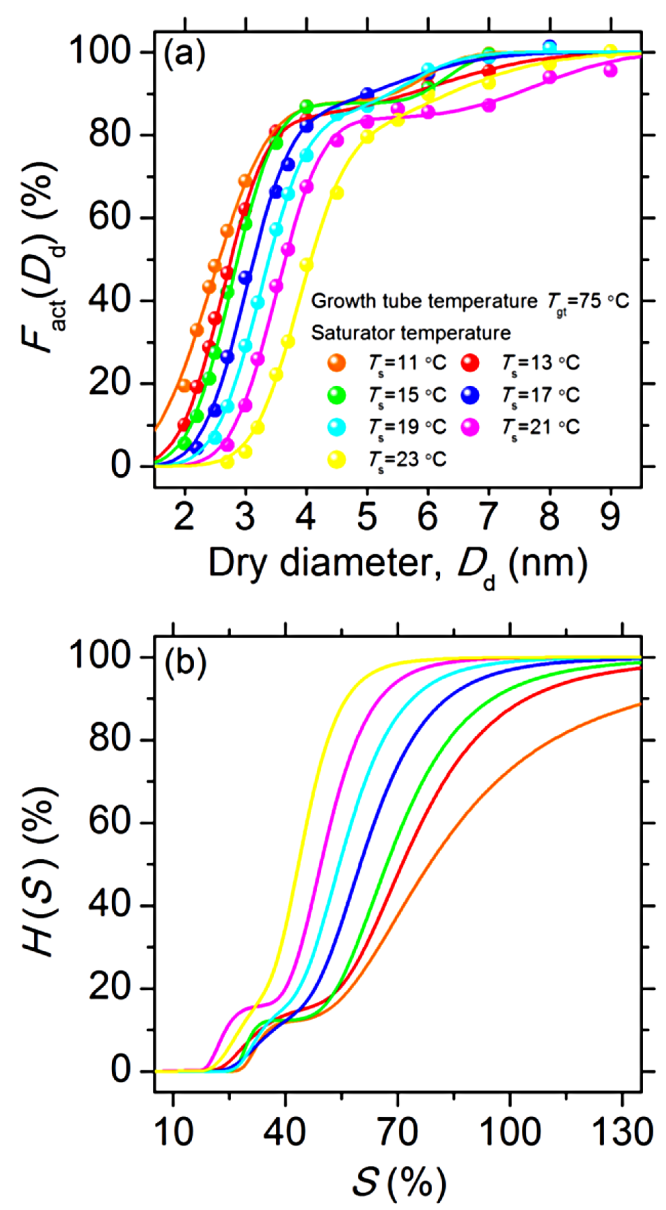

Figure 6. (a) Detection efficiencies of the SS-CPC (filled symbols) for WOx particles. The water-based CPC 3788 was operated with a constant temperature of growth tube $\left(T_{\mathrm{gt}}\right)$ and the varied temperatures of the saturator $\left(T_{\mathrm{S}}\right)$. The different colored lines are fits of a bimodal lognormal cumulative Gaussian distribution function (Eq. 9) to the experimental points, corresponding to the different $T_{\mathrm{S}}$. (b) Cumulative supersaturation distribution $H(S)$ inside CPC retrieved from the activation curve $F_{\text {act }}\left(D_{\mathrm{d}}\right)$ based on Eq. (2). The colored solid lines indicate the different $T_{\mathrm{S}}$, which are in line with panel (a).

where $D$ is the diameter of solution droplet. The parameter $A$ characterizes interactions between adsorbed molecules and between the surface and adjacent adsorbate molecules, while $B$ characterizes the attraction between the solid surface and the adsorbate in subsequent layers. For further details concerning the derivation and explanation of Eq. (10), we refer the reader to Sorjamaa and Laaksonen (2007).

The evaluation of parameters $A$ and $B$ in Eq. (10) are determined by the best fitting between measured and calculated activated fractions $F_{\text {act }}$ for AS particles at $2.5 \mathrm{~nm}$ (Fig. 7), with values of 0.1 and 2.1, respectively. These values are located in the range of previous literature reports $(0.1<A<3$, $0.5<B<3$; Sorjamaa and Laaksonen, 2007, and references therein). Our calculations suggest that with the appropriate 


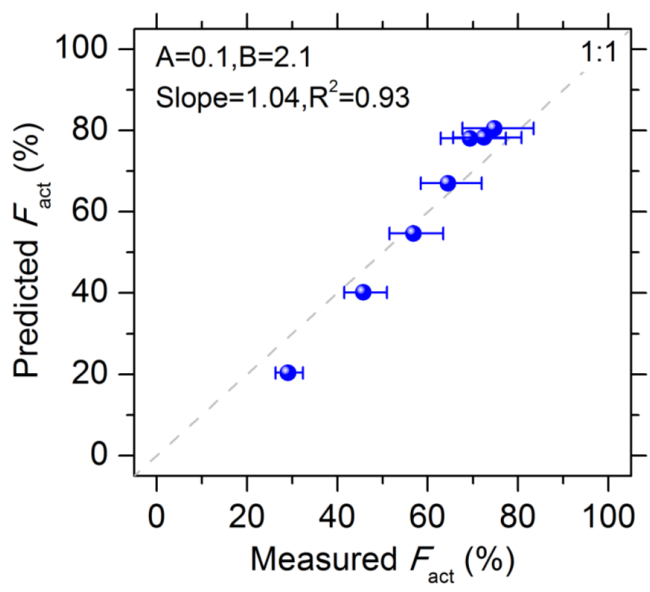

Figure 7. Comparison of measured activation fractions for $2.5 \mathrm{~nm}$ ammonium sulfate particles with those predicted from the modified Köhler equation including the FHH adsorption isotherm (Eq. 10 in the text). The whisker represents the standard deviation caused by the electrometer counting.

parameter values, the activated fractions can be well predicted by the modified Köhler equation with FHH isotherm for the insoluble particles. For $\mathrm{NaCl}$ particles, it is difficult to predict $F_{\text {act }}$ due to its uncertain shape factor. However, if we assume the volume equivalent diameter of $\sim 2.1 \mathrm{~nm}$, we will get similar results as shown in Fig. 7.

\subsection{Characteristic $S$ for $2.5 \mathrm{~nm}$ particles}

For the determination of $S_{\text {cri }}$, we choose $2.5 \mathrm{~nm}$ as the target diameter and select monodisperse $\mathrm{NaCl}, \mathrm{AS}$ and sucrose particles as examples. The activation fractions were determined from results of the electrometer and SS-CPC. Similarly, seven saturator temperatures were tested in our experiments. Figure $8 \mathrm{a}$ shows distinct activation curves of various chemical compounds at $2.5 \mathrm{~nm}$. For the same $T_{\mathrm{S}}($ or $S$ ), $\mathrm{NaCl}$ shows the highest activation fraction $F_{\text {act }}$ while WOx shows the lowest, which is consistent with their hygroscopicities. To reach the same $F_{\text {act }}$ as $\mathrm{NaCl}$, AS would require a $\sim 4 \mathrm{~K}$ lower $T_{\mathrm{s}}$, i.e., a larger temperature gradient and $S$ while a further lower $T_{\mathrm{S}}(\sim 10 \mathrm{~K})$ is needed for sucrose. Such difference in the temperature gradient is significant enough in discriminating the investigated nanoparticles, much higher than the instrument noise $\sim 0.1 \mathrm{~K}$. The hygroscopic-TDMA has been applied with $D_{\mathrm{d}}$ down to $\sim 6 \mathrm{~nm}$ (Biskos et al., 2006a, b; Swietlicki et al., 2008), while size-resolved measurements by traditional CCN counters are limited to $D_{\mathrm{d}}>30 \mathrm{~nm}$ as previously mentioned. We now push this limit down to $2.5 \mathrm{~nm}$.

Figure $8 \mathrm{~b}$ shows the calculated $S_{\text {cri }}$ for various chemical compounds at $2.5 \mathrm{~nm}$. Good agreement between the estimated and theoretical supersaturation has been achieved for AS particles, as indicated in Fig. 7. In summary, our results demonstrate that based on the determined $H(S)$ distributions, the chemical compounds with different hygroscopic-
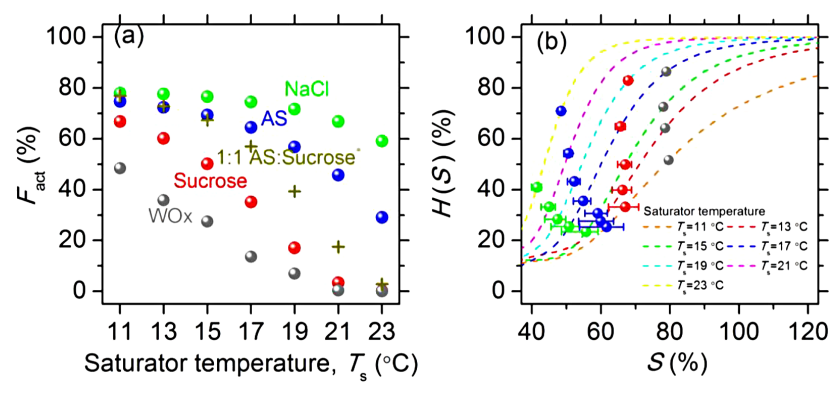

Figure 8. (a) Activation fractions for $2.5 \mathrm{~nm} \mathrm{NaCl}$ (green), AS (blue), sucrose (red) and WOx (gray) aerosols as a function of saturator temperature $T_{\mathrm{S}}$. The mixed AS and sucrose (yellow, mass ratio is $1: 1$ ) aerosols is also shown. Note the experiment of mixed aerosols was done afterwards; hence, it might not represent the real case exactly due to the varied $H(S)$ inside the nano-CCNC; (b) calculated critical supersaturations (filled symbols) for various chemical compounds based on the determined $H(S)$ (Fig. 6b) and measured $F_{\text {act }}$ (Fig. 8a). The colored dash lines indicate the cumulative supersaturation distributions inside the nano-CCNC at different $T_{\mathrm{S}}$. The whisker represents the standard deviation caused by the electrometer counting. Note the points with uncertainties of $S$ higher than $10 \%$ are excluded.

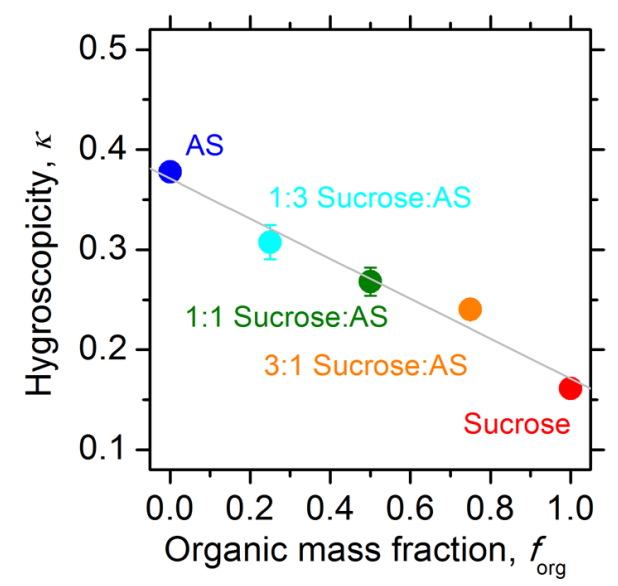

Figure 9. Correlation between the hygroscopicity parameter $\kappa$ and the organic mass fraction $\left(f_{\text {org }}\right)$. Indicated component ratios are mass ratios. The solid line is a linear least square fit with an equation of $\kappa=0.37-0.20 \cdot f_{\text {org }}$ with a correlation coefficient $R$ of 0.98 .

ity can be separated distinctly, especially between representative inorganic (AS, $S=55 \% \pm 5 \%$ ) and organic (sucrose, $S=67 \% \pm 1 \%$ ) compounds.

By measuring the activation behavior of sucrose-AS mixtures, we performed a preliminary test of the relationship between aerosol hygroscopicity and organic mass fraction $\left(f_{\text {org }}\right)$. The result shows a near-linear relationship between $\kappa$ and $f_{\text {org }}$ for nanoparticles of $2.5 \mathrm{~nm}$ (Fig. 9). Here, $f_{\text {org }}$ is the mass fraction of sucrose in mixed solutes that were used to generate aerosol particles. In analogy to the ambient CCN measurements (Gunthe et al., 2009, 2011; Dusek 


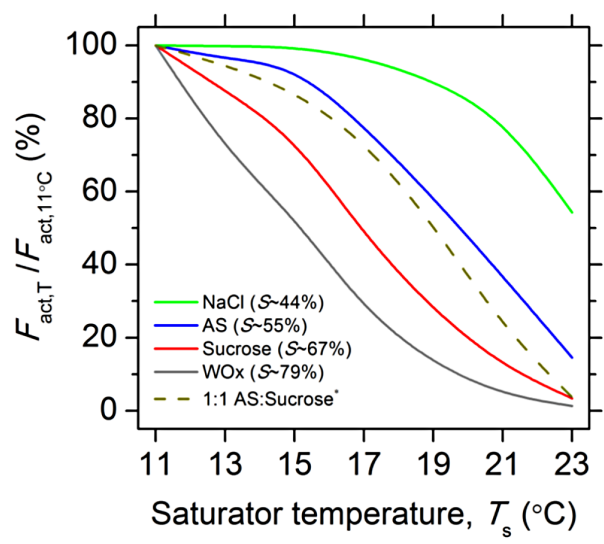

Figure 10. Profiles of relative activation ratio as a function of saturator temperature. The critical supersaturations for $\mathrm{NaCl}, \mathrm{AS}$, sucrose and WOx are average values at seven saturator temperatures. The dash line represents the mixed AS and sucrose aerosols with mass ratio of $1: 1$.

et al., 2010; Rose et al., 2011, 2013), $\kappa$ of lab-generated aerosols (mixtures of sucrose and AS) shows a decreasing trend with the increasing organic mass fraction. Note that the $\kappa$ value of $\sim 0.4$ for $2.5 \mathrm{~nm}$ AS particles is lower than the values reported for larger AS particles $(\sim 0.5-0.8$; Petters and Kreidenweis, 2007; Rose et al., 2008; Mikhailov et al., 2009, 2013), which can be attributed to the concentration dependence of aerosol particle hygroscopicity and nano-size effects on the thermodynamic properties of AS (Cheng et al., 2015).

As previously mentioned, the detection sensitivity of the electrometer precludes its application in ambient measurement. We suggest using the relative activation ratio $R_{H / H_{0}}$ as an alternative parameter. As shown in Fig. 10, different compounds exhibit distinct $R_{H / H_{0}}$ distributions (the ratio of $F_{\text {act, } T}$ to $F_{\text {act, } 11^{\circ} \mathrm{C}}$ ). Their characteristic $S_{\text {cri }}$ can also be determined from $R_{H / H_{0}}$ by Eq. (6). Previous studies (Kulmala et al., 2014, and references therein) have demonstrated that both the ammonium sulfate and organics contribute to the subsequent growth of newly formed particles, which corresponds to the envelope between the AS and WOx profiles.

According to the Köhler equation, different temperatures will also lead to changes in $S_{\text {cri }}$, introducing more complexity in the use of relative activation ratio. To solve this problem, we can take the scanning flow approach for the purpose of varying $S$ so that the temperatures of the saturator and growth tube do not need to change.

\subsection{Solvoscopicity and SS-CPCB}

The concept of scanning supersaturation (SS) is not limited to water-based CPCs, and may also work for CPCs with other working fluids, such as butanol, perfluorotributylamine (Gallar et al., 2006) as well as diethylene glycol (DEG; Vanhanen et al., 2011; Wimmer et al., 2013). In analogy to aerosol "hy- (a)

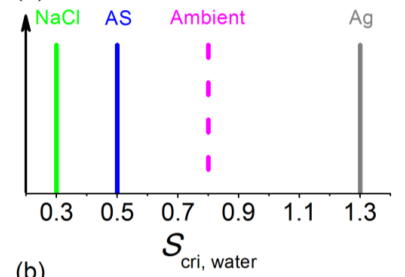

(b)

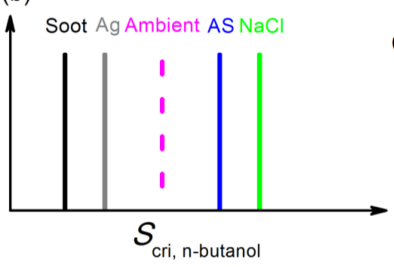

(c)

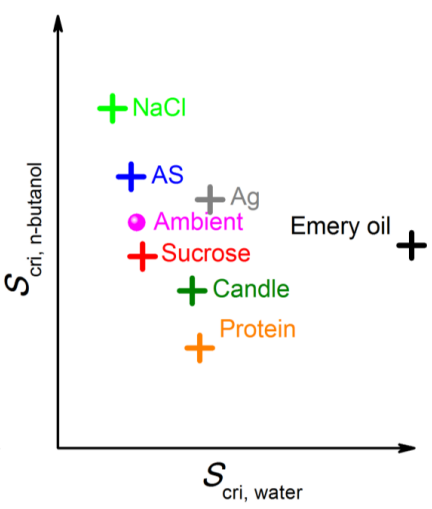

Figure 11. Critical supersaturations $\left(S_{\text {cri }}\right)$ for various chemical compounds in different working fluids: (a) water and (b) $n$-butanol. (c) Schematic of 2-D solvoscopicity distribution matrix. The data set is collected from the previous studies (Hermann et al., 2007; Kulmala et al., 2007; Wang et al., 2010; Kupc et al., 2013).

groscopicity" describing the affinity for water, we introduce the term "solvoscopicity", which from a broad sense, is the ability of a substance to attract and hold solvent molecules. Substances showing higher solvoscopicity for one working liquid may have lower solvoscopicity for another working liquid (Kangasluoma et al., 2014). For example, Fig. 11a-b show that $\mathrm{NaCl}$ is more hygroscopic (higher $S_{\text {cri }}$ and lower $\left.D_{\text {cri }}\right)$ than Ag but become less "solvoscopic" in butanol vapor.

The solvoscopic parameter can be used as "footprint" to estimate/distinguish the aerosol composition. However, it does not work once different substances show similar solvoscopicities, e.g., as sucrose and emery oil in butanol (Fig. 11c). This problem can be solved by performing additional measurements with water-based CPC, in which sucrose and emery oil show distinct hygroscopicities. Therefore, we suggest running multiple CPCs with different working fluids in a SS mode, which gives a SS-CPCB system. Compared to a single SS-CPC, SS-CPCB results in a multiple dimension of $S_{\text {cri }}$ enabling better inference of chemical composition. As shown in Fig. 11c, different inorganic and organic substances as well as metal can be easily distinguished in the 2-D solvoscopicity matrix. The existing CPCB systems (Kulmala et al., 2007; Riipinen et al., 2009; Kangasluoma et al., 2014) can be readily extended to a SS-CPCB system and produce multiple dimensional solvoscopicity matrix.

\section{Conclusion and outlook}

In this study, we present the theoretical basis and design of a nano-CCN counter for the purpose of hygroscopicity measurement in the nano size range (sub-10 nm). The basic con- 
cept is to operate a water-based CPC in a scanning supersaturation mode as a $\mathrm{CCNC}$, recording a composition-dependent activated spectrum and retrieving the solvoscopicity parameter/distribution.

The proof-of-principle experiments were carried out with $2.5 \mathrm{~nm}$ sodium chloride, ammonium sulfate, sucrose and tungsten oxide particles, which show a clear composition dependency and reproducibility of the activation spectra. By using calibration aerosols (WOx), we show the importance of using activation fraction $F_{\text {act }}\left(D_{\mathrm{d}}\right)$ of aerosol samples to calibrate $H(S)$ inside $\mathrm{CPC}$ at different saturator temperatures and its use in the retrieval of aerosol hygroscopicities. As previously mentioned, CCN studies of ambient aerosol particles revealed a near-linear relationship between hygroscopicity parameter $\kappa$ and mass fraction of organics. Our preliminary experiments (on the mixture of sucrose and ammonium sulfate) suggested that the same relationship also holds for nanoparticles down to $2.5 \mathrm{~nm}$.

Though termed as nano-CCNC, the design is not limited to the water-based CPC, but also applies to CPCs with other working fluids. We introduce the term "solvoscopicity" to describe the ability of a substance to attract and hold solvent molecules. Substance solvoscopicity might vary in different working fluids, as demonstrated in hygroscopic/organicTDMA study (Joutsensaari et al., 2001). Compared with single SS-CPC, the SS-CPCB, a combination of CPCs with multiple working fluids in a SS mode, might hence provide further insight into the chemical composition of nanoparticles.

The pulse-height spectra analysis, which has exhibited the ability to differentiate different chemical compounds, can also be utilized in our nano-CCNC study. In addition, a combination of nano-CCNC with nano-HTDMA might provide further insight into the concentration dependence of $\kappa$ values at the nano-size range.

Acknowledgements. This study was supported by the Max Planck Society (MPG), National Science Foundation of China (NSFC, grant no. 41330635), the Minerva Programme, the European Commission under the projects BACCHUS (grant no. 603445) and PEGASOS (grant no. 265148). Xin Wang would like to thank the China Scholarship Council (CSC) and Max Planck Graduate Center (MPGC) for financial support. We gratefully acknowledge P. H. McMurry, T. Klimach, J. Schneider, T. Tritscher (from TSI $\mathrm{GmbH}$ ), F. Tettich and C. Kunath (from GRIMM Aerosol Technik) for encouraging discussions, instrumentation and technical support.

The article processing charges for this open-access publication were covered by the Max Planck Society.

Edited by: F. Pope

\section{References}

Biskos, G., Malinowski, A., Russell, L. M., Buseck, P. R., and Martin, S. T.: Nanosize effect on the deliquescence and the efflorescence of sodium chloride particles, Aerosol Sci. Tech., 40, 97106, doi:10.1080/02786820500484396, 2006a.

Biskos, G., Russell, L. M., Buseck, P. R., and Martin, S. T.: Nanosize effect on the hygroscopic growth factor of aerosol particles, Geophys. Res. Lett., 33, L07801, doi:10.1029/2005GL025199, $2006 b$.

Cerully, K. M., Raatikainen, T., Lance, S., Tkacik, D., Tiitta, P., Petäjä, T., Ehn, M., Kulmala, M., Worsnop, D. R., Laaksonen, A., Smith, J. N., and Nenes, A.: Aerosol hygroscopicity and CCN activation kinetics in a boreal forest environment during the 2007 EUCAARI campaign, Atmos. Chem. Phys., 11, 12369-12386, doi:10.5194/acp-11-12369-2011, 2011.

Chen, D.-R., Pui, D. Y. H., and Kaufman, S. L.: Electrospraying of conducting liquids for monodisperse aerosol generation in the $4 \mathrm{~nm}$ to $1.8 \mu \mathrm{m}$ diameter range, J. Aerosol Sci., 26, 963-977, doi:10.1016/0021-8502(95)00027-A, 1995.

Chen, D. R., Pui, D. Y. H., Hummes, D., Fissan, H., Quant, F. R., and Sem, G. J.: Design and evaluation of a nanometer aerosol differential mobility analyzer (Nano-DMA), J. Aerosol Sci., 29, 497-509, doi:10.1016/S0021-8502(97)10018-0, 1998.

Cheng, Y., Su, H., Koop, T., Mikhailov, E., and Pöschl, U.: Size dependence of phase transitions in aerosol nanoparticles, Nat. Commun., 6, 5923, doi:10.1038/ncomms6923, 2015.

Dusek, U., Frank, G. P., Hildebrandt, L., Curtius, J., Schneider, J., Walter, S., Chand, D., Drewnick, F., Hings, S., Jung, D., Borrmann, S., and Andreae, M. O.: Size matters more than chemistry for cloud-nucleating ability of aerosol particles, Science, 312, 1375-1378, doi:10.1126/science.1125261, 2006.

Dusek, U., Frank, G. P., Curtius, J., Drewnick, F., Schneider, J., Kürten, A., Rose, D., Andreae, M. O., Borrmann, S., and Pöschl, U.: Enhanced organic mass fraction and decreased hygroscopicity of cloud condensation nuclei (CCN) during new particle formation events, Geophys. Res. Lett., 37, L03804, doi:10.1029/2009GL040930, 2010.

Ehn, M., Petäjä, T., Aufmhoff, H., Aalto, P., Hämeri, K., Arnold, F., Laaksonen, A., and Kulmala, M.: Hygroscopic properties of ultrafine aerosol particles in the boreal forest: diurnal variation, solubility and the influence of sulfuric acid, Atmos. Chem. Phys., 7, 211-222, doi:10.5194/acp-7-211-2007, 2007.

Gallar, C., Brock, C. A., Jimenez, J. L., and Simons, C.: A variable supersaturation condensation particle sizer, Aerosol Sci. Tech., 40, 431-436, doi:10.1080/02786820600643339, 2006.

Gunthe, S. S., King, S. M., Rose, D., Chen, Q., Roldin, P., Farmer, D. K., Jimenez, J. L., Artaxo, P., Andreae, M. O., Martin, S. T., and Pöschl, U.: Cloud condensation nuclei in pristine tropical rainforest air of Amazonia: size-resolved measurements and modeling of atmospheric aerosol composition and CCN activity, Atmos. Chem. Phys., 9, 7551-7575, doi:10.5194/acp-9-75512009, 2009.

Gunthe, S. S., Rose, D., Su, H., Garland, R. M., Achtert, P., Nowak, A., Wiedensohler, A., Kuwata, M., Takegawa, N., Kondo, Y., Hu, M., Shao, M., Zhu, T., Andreae, M. O., and Pöschl, U.: Cloud condensation nuclei $(\mathrm{CCN})$ from fresh and aged air pollution in the megacity region of Beijing, Atmos. Chem. Phys., 11, 1102311039, doi:10.5194/acp-11-11023-2011, 2011. 
Hering, S. V., Stolzenburg, M. R., Quant, F. R., Oberreit, D. R., and Keady, P. B.: A Laminar-Flow, Water-Based Condensation Particle Counter (WCPC), Aerosol Sci. Technol., 39, 659-672, doi:10.1080/02786820500182123, 2005.

Hermann, M., Wehner, B., Bischof, O., Han, H. S., Krinke, T., Liu, W., Zerrath, A., and Wiedensohler, A.: Particle counting efficiencies of new TSI condensation particle counters, J. Aerosol Sci., 38, 674-682, doi:10.1016/j.jaerosci.2007.05.001, 2007.

Jayne, J. T., Leard, D. C., Zhang, X., Davidovits, P., Smith, K. A., Kolb, C. E., and Worsnop, D. R.: Development of an Aerosol Mass Spectrometer for Size and Composition Analysis of Submicron Particles, Aerosol Sci. Technol., 33, 49-70, doi:10.1080/027868200410840, 2000.

Jiang, J., Zhao, J., Chen, M., Eisele, F. L., Scheckman, J., Williams, B. J., Kuang, C., and McMurry, P. H.: First measurements of neutral atmospheric cluster and 1-2 nm particle number size distributions during nucleation events, Aerosol Sci. Tech., 45, ii-v, doi:10.1080/02786826.2010.546817, $2011 \mathrm{a}$.

Jiang, J. K., Attoui, M., Heim, M., Brunelli, N. A., McMurry, P. H., Kasper, G., Flagan, R. C., Giapis, K., and Mouret, G.: Transfer functions and penetrations of five differential mobility analyzers for sub-2 $\mathrm{nm}$ particle classification, Aerosol Sci. Tech., 45, 480 492, $2011 b$.

Jokinen, T., Sipilä, M., Junninen, H., Ehn, M., Lönn, G., Hakala, J., Petäjä, T., Mauldin III, R. L., Kulmala, M., and Worsnop, D. R.: Atmospheric sulphuric acid and neutral cluster measurements using CI-APi-TOF, Atmos. Chem. Phys., 12, 4117-4125, doi:10.5194/acp-12-4117-2012, 2012.

Joutsensaari, J., Vaattovaara, P., Vesterinen, M., Hämeri, K., and Laaksonen, A.: A novel tandem differential mobility analyzer with organic vapor treatment of aerosol particles, Atmos. Chem. Phys., 1, 51-60, doi:10.5194/acp-1-51-2001, 2001.

Jurányi, Z., Gysel, M., Weingartner, E., DeCarlo, P. F., Kammermann, L., and Baltensperger, U.: Measured and modelled cloud condensation nuclei number concentration at the high alpine site Jungfraujoch, Atmos. Chem. Phys., 10, 7891-7906, doi:10.5194/acp-10-7891-2010, 2010.

Kangasluoma, J., Kuang, C., Wimmer, D., Rissanen, M. P., Lehtipalo, K., Ehn, M., Worsnop, D. R., Wang, J., Kulmala, M., and Petäjä, T.: Sub-3 nm particle size and composition dependent response of a nano-CPC battery, Atmos. Meas. Tech., 7, 689-700, doi:10.5194/amt-7-689-2014, 2014.

Kerminen, V.-M., Paramonov, M., Anttila, T., Riipinen, I., Fountoukis, C., Korhonen, H., Asmi, E., Laakso, L., Lihavainen, H., Swietlicki, E., Svenningsson, B., Asmi, A., Pandis, S. N., Kulmala, M., and Petäjä, T.: Cloud condensation nuclei production associated with atmospheric nucleation: a synthesis based on existing literature and new results, Atmos. Chem. Phys., 12, 12037 12059, doi:10.5194/acp-12-12037-2012, 2012.

Kulkarni, P., Baron, P. A., and Willeke, K.: Aerosol Measurement: Principles, Techniques, and Applications, 3rd Edition, John Wiley \& Sons, Inc, Hoboken, New Jersey, USA, 2011.

Kulmala, M., Pirjola, L., and Makela, J. M.: Stable sulphate clusters as a source of new atmospheric particles, Nature, 404, 66-69, 2000.

Kulmala, M., Mordas, G., Petäjä, T., Grönholm, T., Aalto, P. P., Vehkamäki, H., Hienola, A. I., Herrmann, E., Sipilä, M., Riipinen, I., Manninen, H. E., Hämeri, K., Stratmann, F., Bilde, M., Winkler, P. M., Birmili, W., and Wagner, P. E.: The condensation particle counter battery (CPCB): a new tool to investigate the activation properties of nanoparticles, J. Aerosol Sci., 38, 289-304, doi:10.1016/j.jaerosci.2006.11.008, 2007.

Kulmala, M., Petäjä, T., Nieminen, T., Sipilä, M., Manninen, H. E., Lehtipalo, K., Dal Maso, M., Aalto, P. P., Junninen, H., Paasonen, P., Riipinen, I., Lehtinen, K. E. J., Laaksonen, A., and Kerminen, V.-M.: Measurement of the nucleation of atmospheric aerosol particles, Nat. Protocols, 7, 1651-1667, doi:10.1038/nprot.2012.091, 2012.

Kulmala, M., Kontkanen, J., Junninen, H., Lehtipalo, K., Manninen, H. E., Nieminen, T., Petäjä, T., Sipilä, M., Schobesberger, S., Rantala, P., Franchin, A., Jokinen, T., Järvinen, E., Äijälä, M., Kangasluoma, J., Hakala, J., Aalto, P. P., Paasonen, P., Mikkilä, J., Vanhanen, J., Aalto, J., Hakola, H., Makkonen, U., Ruuskanen, T., Mauldin, R. L., Duplissy, J., Vehkamäki, H., Bäck, J., Kortelainen, A., Riipinen, I., Kurtén, T., Johnston, M. V., Smith, J. N., Ehn, M., Mentel, T. F., Lehtinen, K. E. J., Laaksonen, A., Kerminen, V.-M., and Worsnop, D. R.: Direct observations of atmospheric aerosol nucleation, Science, 339, 943-946, doi:10.1126/science.1227385, 2013.

Kulmala, M., Petäjä, T., Ehn, M., Thornton, J., Sipilä, M., Worsnop, D. R., and Kerminen, V.-M.: Chemistry of atmospheric nucleation: on the recent advances on precursor characterization and atmospheric cluster composition in connection with atmospheric new particle formation, Annu. Rev. Phys. Chem., 65, $21-$ 37, doi:10.1146/annurev-physchem-040412-110014, 2014.

Kupc, A., Bischof, O., Tritscher, T., Beeston, M., Krinke, T., and Wagner, P. E.: Laboratory characterization of a new nanowater-based CPC 3788 and performance comparison to an ultrafine butanol-based CPC 3776, Aerosol Sci. Tech., 47, 183-191, doi:10.1080/02786826.2012.738317, 2013.

Lance, S.: Quantifying compositional impacts of ambient aerosol on cloud droplet formation, $\mathrm{PhD}$ thesis, Georgia Institute of Technology, Atlanta, GA, 2007.

Lance, S., Nenes, A., Medina, J., and Smith, J. N.: Mapping the operation of the DMT Continuous Flow CCN Counter, Aerosol Sci. Tech., 40, 242-254, doi:10.1080/02786820500543290, 2006.

Lance, S., Raatikainen, T., Onasch, T. B., Worsnop, D. R., Yu, X.-Y., Alexander, M. L., Stolzenburg, M. R., McMurry, P. H., Smith, J. N., and Nenes, A.: Aerosol mixing state, hygroscopic growth and cloud activation efficiency during MIRAGE 2006, Atmos. Chem. Phys., 13, 5049-5062, doi:10.5194/acp-13-5049-2013, 2013.

Lathem, T. L., Beyersdorf, A. J., Thornhill, K. L., Winstead, E. L., Cubison, M. J., Hecobian, A., Jimenez, J. L., Weber, R. J., Anderson, B. E., and Nenes, A.: Analysis of CCN activity of Arctic aerosol and Canadian biomass burning during summer 2008, Atmos. Chem. Phys., 13, 2735-2756, doi:10.5194/acp-13-27352013, 2013.

Lehtipalo, K., Leppä, J., Kontkanen, J., Kangasluoma, J., Franchin, A., Wimmer, D., Schobesberger, S., Junninen, H., Petäjä, T., Sipilä, M., Mikkilä, J., Vanhanen, J., Worsnop, D. R., and Kulmala, M.: Methods for determining particle size distribution and growth rates between 1 and $3 \mathrm{~nm}$ using the Particle Size Magnifier, Boreal Environ. Res., 19, 215-236, 2014.

Marti, J. J., Weber, R. J., Saros, M. T., Vasiliou, J. G., and McMurry, P. H.: Modification of the TSI 3025 Condensation Particle Counter for pulse height analysis, Aerosol Sci. Tech., 25, 214-218, doi:10.1080/02786829608965392, 1996. 
McDermott, W. T., Ockovic, R. C., and Stolzenburg, M. R.: Counting efficiency of an improved $30-\AA$ condensation nucleus counter, Aerosol Sci. Tech., 14, 278-287, doi:10.1080/02786829108959490, 1991.

McMurry, P. H.: The history of condensation nucleus counters, Aerosol Sci. Tech., 33, 297-322, doi:10.1080/02786820050121512, 2000a.

McMurry, P. H.: A review of atmospheric aerosol measurements, Atmos. Environ., 34, 1959-1999, 2000 b.

Mei, F., Hayes, P. L., Ortega, A., Taylor, J. W., Allan, J. D., Gilman, J., Kuster, W., de Gouw, J., Jimenez, J. L., and Wang, J.: Droplet activation properties of organic aerosols observed at an urban site during CalNex-LA, J. Geophys. Res.-Atmos., 118, 2903-2917, doi:10.1002/jgrd.50285, 2013.

Mikhailov, E., Vlasenko, S., Martin, S. T., Koop, T., and Pöschl, U.: Amorphous and crystalline aerosol particles interacting with water vapor: conceptual framework and experimental evidence for restructuring, phase transitions and kinetic limitations, Atmos. Chem. Phys., 9, 9491-9522, doi:10.5194/acp-9-9491-2009, 2009

Mikhailov, E., Vlasenko, S., Rose, D., and Pöschl, U.: Mass-based hygroscopicity parameter interaction model and measurement of atmospheric aerosol water uptake, Atmos. Chem. Phys., 13, $717-$ 740, doi:10.5194/acp-13-717-2013, 2013.

Moore, R. H. and Nenes, A.: Scanning flow CCN analysis a method for fast measurements of CCN spectra, Aerosol Sci. Tech., 43, 1192-1207, doi:10.1080/02786820903289780, 2009.

Moore, R. H., Nenes, A., and Medina, J.: Scanning mobility CCN analysis - a method for fast measurements of size-resolved CCN distributions and activation kinetics, Aerosol Sci. Tech., 44, 861871, doi:10.1080/02786826.2010.498715, 2010.

Mordas, G., Manninen, H. E., Petäjä, T., Aalto, P. P., Hämeri, K., and Kulmala, M.: On operation of the ultra-fine water-based CPC TSI 3786 and comparison with other TSI models (TSI 3776, TSI 3772, TSI 3025, TSI 3010, TSI 3007), Aerosol Sci. Tech., 42, 152-158, doi:10.1080/02786820701846252, 2008.

O’Dowd, C. D., Aalto, P., Hmeri, K., Kulmala, M., and Hoffmann, T.: Aerosol formation: Atmospheric particles from organic vapours, Nature, 416, 497-498, 2002.

O'Dowd, C. D., Aalto, P. P., Yoon, Y. J., and Hämeri, K.: The use of the pulse height analyser ultrafine condensation particle counter (PHA-UCPC) technique applied to sizing of nucleation mode particles of differing chemical composition, J. Aerosol Sci., 35, 205-216, doi:10.1016/j.jaerosci.2003.08.003, 2004.

Petters, M. D. and Kreidenweis, S. M.: A single parameter representation of hygroscopic growth and cloud condensation nucleus activity, Atmos. Chem. Phys., 7, 1961-1971, doi:10.5194/acp-71961-2007, 2007.

Petters, M. D., Carrico, C. M., Kreidenweis, S. M., Prenni, A. J., DeMott, P. J., Collett Jr., J. L., and Moosmüller, H.: Cloud condensation nucleation activity of biomass burning aerosol, J. Geophys. Res., 114, D22205, doi:10.1029/2009jd012353, 2009.

Pöschl, U., Martin, S. T., Sinha, B., Chen, Q., Gunthe, S. S., Huffman, J. A., Borrmann, S., Farmer, D. K., Garland, R. M., Helas, G., Jimenez, J. L., King, S. M., Manzi, A., Mikhailov, E., Pauliquevis, T., Petters, M. D., Prenni, A. J., Roldin, P., Rose, D., Schneider, J., Su, H., Zorn, S. R., Artaxo, P., and Andreae, M. O.: Rainforest aerosols as biogenic nuclei of clouds and precipitation in the Amazon, Science, 329, 1513-1516, doi:10.1126/science.1191056, 2010.

Pruppacher, H. R. and Klett, J. D.: Microphysics of Clouds and Precipitation, Kluwer Academic Publishers, Dordrecht, the Netherlands, 2000.

Riipinen, I., Manninen, H. E., Yli-Juuti, T., Boy, M., Sipilä, M., Ehn, M., Junninen, H., Petäjä, T., and Kulmala, M.: Applying the Condensation Particle Counter Battery (CPCB) to study the water-affinity of freshly-formed 2-9 $\mathrm{nm}$ particles in boreal forest, Atmos. Chem. Phys., 9, 3317-3330, doi:10.5194/acp-9-33172009, 2009.

Rose, D., Gunthe, S. S., Mikhailov, E., Frank, G. P., Dusek, U., Andreae, M. O., and Pöschl, U.: Calibration and measurement uncertainties of a continuous-flow cloud condensation nuclei counter (DMT-CCNC): CCN activation of ammonium sulfate and sodium chloride aerosol particles in theory and experiment, Atmos. Chem. Phys., 8, 1153-1179, doi:10.5194/acp-8-11532008, 2008.

Rose, D., Nowak, A., Achtert, P., Wiedensohler, A., Hu, M., Shao, M., Zhang, Y., Andreae, M. O., and Pöschl, U.: Cloud condensation nuclei in polluted air and biomass burning smoke near the mega-city Guangzhou, China - Part 1: Size-resolved measurements and implications for the modeling of aerosol particle hygroscopicity and CCN activity, Atmos. Chem. Phys., 10, 3365 3383, doi:10.5194/acp-10-3365-2010, 2010.

Rose, D., Gunthe, S. S., Su, H., Garland, R. M., Yang, H., Berghof, M., Cheng, Y. F., Wehner, B., Achtert, P., Nowak, A., Wiedensohler, A., Takegawa, N., Kondo, Y., Hu, M., Zhang, Y., Andreae, M. O., and Pöschl, U.: Cloud condensation nuclei in polluted air and biomass burning smoke near the mega-city Guangzhou, China - Part 2: Size-resolved aerosol chemical composition, diurnal cycles, and externally mixed weakly $\mathrm{CCN}$-active soot particles, Atmos. Chem. Phys., 11, 2817-2836, doi:10.5194/acp-112817-2011, 2011

Rose, D., Gunthe, S. S., Jurányi, Z., Gysel, M., Frank, G. P., Schneider, J., Curtius, J., and Pöschl, U.: Size-resolved and integral measurements of cloud condensation nuclei $(\mathrm{CCN})$ at the high-alpine site Jungfraujoch, Atmos. Chem. Phys. Discuss., 13, 32575-32624, doi:10.5194/acpd-13-32575-2013, 2013.

Sakurai, H., Fink, M. A., McMurry, P. H., Mauldin, L., Moore, K. F., Smith, J. N., and Eisele, F. L.: Hygroscopicity and volatility of 4-10 nm particles during summertime atmospheric nucleation events in urban Atlanta, J. Geophys. Res.-Atmos., 110, D22S04, doi:10.1029/2005jd005918, 2005.

Saros, M. T., Weber, R. J., Marti, J. J., and McMurry, P. H.: Ultrafine aerosol measurement using a condensation nucleus counter with pulse height analysis, Aerosol Sci. Tech., 25, 200-213, doi:10.1080/02786829608965391, 1996.

Sipilä, M., Lehtipalo, K., Attoui, M., Neitola, K., Petäjä, T., Aalto, P. P., O'Dowd, C. D., and Kulmala, M.: Laboratory Verification of PH-CPC's Ability to Monitor Atmospheric Sub-3 nm Clusters, Aerosol Sci. Technol., 43, 126-135, doi:10.1080/02786820802506227, 2009.

Smith, J. N., Moore, K. F., McMurry, P. H., and Eisele, F. L.: Atmospheric measurements of sub- $20 \mathrm{~nm}$ diameter particle chemical composition by thermal desorption chemical ionization mass spectrometry, Aerosol Sci. Tech., 38, 100-110, doi:10.1080/02786820490249036, 2004. 
Snider, J. R., Wex, H., Rose, D., Kristensson, A., Stratmann, F., Hennig, T., Henning, S., Kiselev, A., Bilde, M., Burkhart, M., Dusek, U., Frank, G. P., Kiendler-Scharr, A., Mentel, T. F., Petters, M. D., and Pöschl, U.: Intercomparison of cloud condensation nuclei and hygroscopic fraction measurements: coated soot particles investigated during the LACIS Experiment in November (LExNo), J. Geophys. Res.-Atmos., 115, D11205, doi:10.1029/2009JD012618, 2010.

Sorjamaa, R. and Laaksonen, A.: The effect of $\mathrm{H} 2 \mathrm{O}$ adsorption on cloud drop activation of insoluble particles: a theoretical framework, Atmos. Chem. Phys., 7, 6175-6180, doi:10.5194/acp-76175-2007, 2007.

Steiner, G.: Generierung von Nanopartikeln - Über die Konstruktion eines Heizdraht-Wolframoxidgenerators, Master Thesis, Faculty of Physics, University of Vienna, Vienna, Austria, 2006.

Stolzenburg, M. R.: An Ultrafine Aerosol Size DistributionMeasuring System, PhD thesis, Mechanical Engineering Department, University of Minnesota, Minneapolis, USA, 1988.

Stolzenburg, M. R. and McMurry, P. H.: An ultrafine aerosol condensation nucleus counter, Aerosol Sci. Tech., 14, 48-65, doi:10.1080/02786829108959470, 1991.

Stolzenburg, M. R. and McMurry, P. H.: Equations governing single and tandem DMA configurations and a new lognormal approximation to the transfer function, Aerosol Sci. Tech., 42, 421-432, doi:10.1080/02786820802157823, 2008.

Su, H., Rose, D., Cheng, Y. F., Gunthe, S. S., Massling, A., Stock, M., Wiedensohler, A., Andreae, M. O., and Pöschl, U.: Hygroscopicity distribution concept for measurement data analysis and modeling of aerosol particle mixing state with regard to hygroscopic growth and CCN activation, Atmos. Chem. Phys., 10, 7489-7503, doi:10.5194/acp-10-7489-2010, 2010.

Swietlicki, E., Hansson, H. C., Hämeri, K., Svenningsson, B., Massling, A., McFiggans, G., McMurry, P. H., Petäjä, T., Tunved, P., Gysel, M., Topping, D., Weingartner, E., Baltensperger, U., Rissler, J., Wiedensohler, A., and Kulmala, M.: Hygroscopic properties of submicrometer atmospheric aerosol particles measured with H-TDMA instruments in various environments - a review, Tellus B, 60, 432-469, doi:10.1111/j.16000889.2008.00350.x, 2008.

Vanhanen, J., Mikkilä, J., Lehtipalo, K., Sipilä, M., Manninen, H. E., Siivola, E., Petäjä, T., and Kulmala, M.: Particle Size Magnifier for Nano-CN Detection, Aerosol Sci. Technol., 45, 533-542, doi:10.1080/02786826.2010.547889, 2011.

Wang, S. and Johnston, M. V.: Airborne nanoparticle characterization with a digital ion trap-reflectron time of flight mass spectrometer, Int. J. Mass Spectrom., 258, 50-57, doi:10.1016/j.ijms.2006.07.001, 2006.
Wang, X., Caldow, R., Sem, G. J., Hama, N., and Sakurai, H.: Evaluation of a condensation particle counter for vehicle emission measurement: experimental procedure and effects of calibration aerosol material, J. Aerosol Sci., 41, 306-318, doi:10.1016/j.jaerosci.2010.01.001, 2010.

Weber, R. J., Stolzenburg, M. R., Pandis, S. N., and McMurry, P. H.: Inversion of ultrafine condensation nucleus counter pulse height distributions to obtain nanoparticle $(\sim 3-10 \mathrm{~nm})$ size distributions, J. Aerosol Sci., 29, 601-615, doi:10.1016/S00218502(97)10026-X, 1998.

Wiedensohler, A., Aalto, P., Covert, D., Heintzenberg, J., and McMurry, P. H.: Intercomparison of four methods to determine size distributions of low-concentration ( $\left.100 \mathrm{~cm}^{-3}\right)$, ultrafine aerosols $\left(3<D_{\mathrm{p}}<10 \mathrm{~nm}\right)$ with illustrative data from the Arctic, Aerosol Sci. Tech., 21, 95-109, doi:10.1080/02786829408959700, 1994.

Wiedensohler, A., Cheng, Y. F., Nowak, A., Wehner, B., Achtert, P., Berghof, M., Birmili, W., Wu, Z. J., Hu, M., Zhu, T., Takegawa, N., Kita, K., Kondo, Y., Lou, S. R., Hofzumahaus, A., Holland, F., Wahner, A., Gunthe, S. S., Rose, D., Su, H., and Pöschl, U.: Rapid aerosol particle growth and increase of cloud condensation nucleus activity by secondary aerosol formation and condensation: a case study for regional air pollution in northeastern China, J. Geophys. Res., 114, D00G08, doi:10.1029/2008JD010884, 2009.

Wimmer, D., Lehtipalo, K., Franchin, A., Kangasluoma, J., Kreissl, F., Kürten, A., Kupc, A., Metzger, A., Mikkilä, J., Petäjä, T., Riccobono, F., Vanhanen, J., Kulmala, M., and Curtius, J.: Performance of diethylene glycol-based particle counters in the sub-3 nm size range, Atmos. Meas. Tech., 6, 1793-1804, doi:10.5194/amt-6-1793-2013, 2013.

Wu, Z. J., Poulain, L., Henning, S., Dieckmann, K., Birmili, W., Merkel, M., van Pinxteren, D., Spindler, G., Müller, K., Stratmann, F., Herrmann, H., and Wiedensohler, A.: Relating particle hygroscopicity and $\mathrm{CCN}$ activity to chemical composition during the HCCT-2010 field campaign, Atmos. Chem. Phys., 13, 79837996, doi:10.5194/acp-13-7983-2013, 2013.

Zhang, R., Khalizov, A., Wang, L., Hu, M., and Xu, W.: Nucleation and growth of nanoparticles in the atmosphere, Chem. Rev., 112, 1957-2011, doi:10.1021/cr2001756, 2012.

Zhao, J., Eisele, F. L., Titcombe, M., Kuang, C., and McMurry, P. H.: Chemical ionization mass spectrometric measurements of atmospheric neutral clusters using the cluster-CIMS, J. Geophys. Res.-Atmos., 115, D08205, doi:10.1029/2009jd012606, 2010. 